\title{
Governing and Managing Customer-Initiated Engineering Change: An In-Depth Case Study of a Global Industrial Supplier
}

\author{
Anita Friis Sommer, Simon Haahr Storbjerg, \\ Iskra Dukovska-Popovska, and Kenn Steger-Jensen \\ Institute for Mechanical Engineering and Production, Aalborg University, Denmark \\ (sommer, shs, iskra, kenn) @m-tech.aau.dk
}

\begin{abstract}
Engineering change management is managing an alteration made to the technical system and/or its related value chain processes and documentation that have already been released during the product and process design process. The change can either emerge during the process or be initiated internally or externally by for instance customers. Managing initiated engineering changes is a vital source for improving product performance and radically reducing change costs. Customer-initiated engineering change is an area growing in importance decreasing product life cycles and increasing demand for customisation. Through an in-depth case study, this paper investigates which process and what governance setup is appropriate to manage customer initiated engineering changes, referred to as request management. The paper includes a proposal for a request management framework and a task-based iterative process model based on existing engineering change management theory and case study findings.
\end{abstract}

Keywords: Engineering change management, customer-initiated change management, request management, case study.

\section{$1 \quad$ Introduction}

Shortening product life cycles and increasing customer demands are inevitable parts of the on-going change in today's industrial markets [1]. Changes in customer products creates in many cases a need for change in supplier products due to product interdependencies [2]. Consequently suppliers now face an increasing need to develop a request management process to handle the increasing amount of external requests for product changes [2]. Changes to existing products may encompass all levels of innovation from incremental changes to radical innovation [3, 4]. Engineering Change Management (ECM) is a research area that has gained increased attention during recent years [4]. In its initial scope, ECM was mainly viewed as a process for managing design oscillations in interdependent product parts during new product development [5]. Now the scope has been broadened, and ECM is considered relevant in all stages of the product life cycle $[6,7]$. Research topics of increasing interest within ECM include among others, managing customer-initiated engineering change 
[8]. Researchers are still to unfold and understand the customer-initiated ECM process and enabling processes including governance mechanisms, and how this ECM process diverts from internally initiated ECM [2]. For instance, customer-initiated ECM is expected to include other challenges than internally initiated ECM related to for instance customer-supplier interaction, customer relationship management, impact analysis, portfolio management, and cross-organizational knowledge management. In this paper, we have chosen to use the term request management for customer-initiated ECM. The aim of this research is to investigate which ECM process and process governance approach is appropriate for request management. The paper is structured as follows: Firstly, the theoretical background is introduced including ECM, ECM governance, and customer-initiated ECM. Secondly, the research method is presented including description of the case company, which is used for an in-depth investigation. Finally, the results are presented and analyzed, providing a proposal for a request management framework, followed by a brief discussion and a conclusion.

\section{Theoretical Background}

This section will provide the theoretical background. First the research area of ECM is introduced followed by a presentation of existing research on customer-initiated change management. Based on the literature we propose a framework for request management, which is used in the following method and analysis.

\subsection{Engineering Changes}

The phenomenon of engineering change has been a topic for research in several years. One of the earliest contributions having engineering change as the primary topic is noted to be Dale in 1982 [9] [10]. Since his study, several other contributions have been given and the research on engineering change has expanded into several different focus areas. Making all design decisions right the first time is clearly an illusion; designing is an iterative process meaning that changes to existing design decisions are inevitable [5]. Furthermore, for the majority of manufacturing companies, design is not a single event for a single technical system, but a repetitive activity for portfolios or families of products and services introducing both simultaneous variants and generational variants. In many cases design does not begin with a blank sheet, but originates from already existing design. As a collective name, these changes have been termed "engineering changes" [4]. Based on case studies several definitions have been given in literature, the definition in closest to the authors experience is brought by Jarratt, Eckert, Caldwell and Clarkson [4]: "An engineering change is an alteration made to parts, drawings or software that has already been released during the product design process, regardless of the scale of the change." This paper takes an even broader perspective, engineering change is thus defined as; 'an alteration made to the technical system and/or its related value chain processes and documentation that has already been released during the product and process design process'. 
One of the fundamental characteristics of a system is that the parts that make up the system are interrelated [11]. In products these relations can take on many forms, e.g. mechanical, electrical, thermal etc. and are most often difficult to foresee, especially in complex systems [5]. Given these relations, making changes to existing design i.e. technical systems is very seldom having isolated effects. As a consequence introducing an engineering change most often cause several other changes. This nature of change is highlighted by several, and framed in the term change propagation, which refers to the process by which an engineering change to parts of a product results in one or more additional engineering changes to other parts of the products [12]. In addition to the complex cause-effect patterns of introducing engineering changes to technical systems, the management of engineering changes involves a complex web of stakeholders. The importance of doing thorough ECM is thus only further underlined when the organizational perspective is considered. Fricke, Gebhard, Negele and Igenbergs [6] also states straight-forwardly that ultimately two alternatives exist without an adequate ECM: to die of changes, or to miss the chance of successful products.

Concerning the source of the engineering change, two fundamental types of changes exists; changes that have to be avoided, e.g. changes which are consequences of bad design decisions or propagation effects, and changes which are an opportunity for the company e.g. changes that facilitate the continuous innovation [6]. These two types of changes are in literature most often referred to as emergent changes and initiated changes. Eckert, Clarkson and Zanker [8] define these two types as: Emergent changes - changes that are caused by the state of the design, where problems occurring across the whole design and throughout the product life cycle can lead to changes. Initiated changes - changes arising from an outside source, typically a new requirement from customers, certification bodies, or initiated by the manufacturer. This paper supports the perspective that engineering changes occur throughout the entire product life cycle [7], and that engineering changes can range from minor changes to more complex changes affecting several modules and systems [4]. Concerning the object of change, the types of engineering changes depends on the contextual scope and setup of ECM, and thus several different types of ECM exist. It is the authors' experience that most often the scope of ECM covers changes to primary design documentation, e.g. drawings, 3D-models, Bill of Materials (BOMs) and system changes, e.g. ERP or MRP master data. In some firms engineering changes also encompass changes in process documentation, e.g. work instructions, and routings, and secondary design documentation, as e.g. design failure mode analysis and design verification plans.

\subsection{Managing Engineering Change Processes}

As highlighted by Jarratt, Eckert, Caldwell and Clarkson [4] different authors have proposed distinct engineering change processes. They divide the process into different numbers of phases. For example, Dale [9] proposes a formal process split into two phases, whereas Maull, Hughes and Bennett [13] suggests a process made up of five parts. Despite the different types of engineering changes, the literature has so far only 
briefly addressed different types of ECM processes. Generally speaking, two fundamental types of ECM processes are described in literature, a formal and linear process and an informal and more ad-hoc approach. A highly central element of the ECM process is ensuring a proper evaluation of the proposed change based on impact analysis., e.g. Huang and Mak [10] propose that evaluating changes quickly as one of 13 guidelines for efficient ECM, similarly Eckert, Clarkson and Zanker [8] conclude that successful ECM requires knowledge on the consequences of a change on product quality, cost, and time to market. Change evaluation and impact analysis is also addressed as a separate theme in several other publications [12, 14, 15]. A topic not addressed in literature is how to ensure that proper impact assessment is being done when a more iterative change process is needed as in the change process described in the case study of this paper. In existing literature several governance mechanisms are described including governance structures and enabling processes. The term business process governance refers to the direction, coordination, and control of individuals, groups, or organizations that are at least to some extent autonomous: that is, not directly subject to the same hierarchical authority [16]. Business process governance encompasses a variety of mechanisms including laws, rules and personal mechanisms administered by individuals [16]. These mechanisms are considered to be at least as important as managing the ECM process itself, since the ECM process spans both functional and organizational boundaries. The identified ECM governance mechanisms are divided according to the four management aspects technology, organization, people and strategy, introduced by [17], and enabling management processes:

- $\quad$ Technological aspects - ECM systems, Product Data Management (PDM) systems, and CAD/CAM systems [2, 10, 18]

- Organizational aspects - Decision making structure and processes, ECM roles and responsibilities [8, 10, 19]

- People aspects - Skills and competencies, team working, training, learning $[2,8,20]$

- $\quad$ Strategic aspects - ECM strategy $[4,6]$

- Enabling management processes - Portfolio management, resource management, knowledge management, visual management, performance management $[4,20,21]$

\subsection{Customer-Initiated Engineering Change}

Customer-initiated engineering changes are regarded to be a value adding activity [2]. Based on multiple case studies Wasmer, Staub and Vroom [2] develop an information system solution for customer-initiated ECM, with the purpose of enabling companies to accept more customer requests within the same financial limitations. The goal of an ECM information system is to make the process more dynamic by facilitating crossorganizational interaction [2]. The information system functions as a governance structure increasing transparency of the process and facilitating communication and knowledge sharing. To the authors' knowledge, this is the first research study on 
governance mechanisms of customer-initiated engineering change, and so far no overview of governance aspects within this area exists.

The information system developed by Wasmer, Staub and Vroom [2] is successfully implemented and tested, and they report positive results including process lead-time improvements by $20-40 \%$. In this paper, customer-initiated ECM is termed request management, since this type of ECM revolves around management of a customer request for engineering change. Based on the review of existing literature, a systemic process framework for request management is proposed, which is presented in figure 1. The framework includes the ECM process, process governance, and specifies process characteristics of request management.

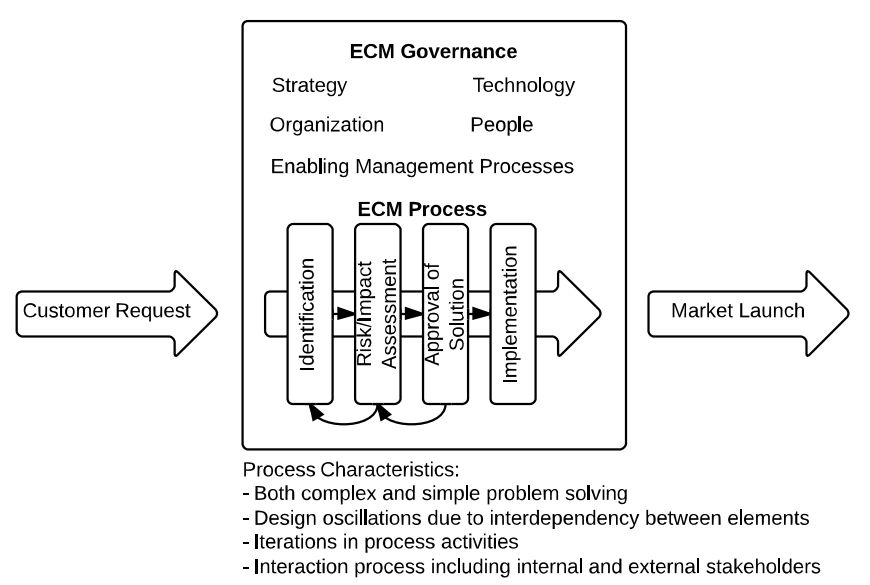

Fig. 1. Systemic Process Framework for Request Management inspired by existing ECM research

\section{$3 \quad$ Method}

This research includes an in-depth case study, which is conducted using design science research [22]. Design science research is a design-oriented, prescriptive research approach [23]. The purpose of design science is to: “... develop knowledge that the professionals of the discipline in question can use to design solution for their field problems" [24]. At its core, design science is directed toward understanding and improving the search among potential components in order to construct an artifact that is intended to solve a problem [25, 26]. Design science research is sometimes called "Improvement Research" and this designation emphasizes the problemsolving/performance-improving nature of the activity [27]. Suggestions for a problem solution are abductively drawn from the existing knowledge/theory base for the problem area [27, 28]. Design science can be viewed as a research paradigm, revolving around development and implementation of artefacts [29, 30]. The method 
includes elements of abductive reasoning and deductive reasoning, and consists of five iterative phases; awareness of problem, suggestion, development, evaluation, conclusion [31]. During the first two phases the problem is realized and a suggestion for solution is made through abduction. Operations management is essentially a practical field dealing with practical problems [23, 32], and like a large number of researchers we assume the role of problem solver, actively seeking to develop solutions, not merely explanations. The case includes a three-year collaboration project from 2010 to 2012 (both years included) between the research team and a large industrial manufacturer, here referred to as Alpha. Both parties agree on joint problem solving for the company and it's customers, and it is agreed that all data can be used for scientific purposes, but without publication of the company's name. The objective for the case company is to develop and implement a solution for request management, which can be used in the existing manufacture-to-stock setup.

During the collaboration period, cross-organizational interview studies were made before and after implementation of the solution. In total, 20 formal and more than 30 informal interviews was conducted internally, and additionally formal interviews was conducted with four manufacturing customers. The formal interviews included a semi-structured interview guide. The interviews aimed at identifying the activity flow of the request process, the governance aspects, and understand how coordination and collaboration is conducted in practice. Furthermore, the study aimed at identifying current challenges in the process, and how a future ideal solution could be for the interviewee. Finally, a set of questions was aimed at identifying the current strengths of the process, to develop a nuanced understanding of the process, not simply focusing on problem solving, but also considering the strengths of the existing process. Interviews were analysed using open coding and pattern matching in relation to the request management framework [33,34]. Information on data handling and documentation was collected through available information in the IT system, which included spread sheets, email threads and data in the customer relationship management system, and analysed in relation to the identified needs of a request management process. Researchers have influenced development and implementation of the solution by communicating results of interview studies and data analysis to involved managers, both recurring to local management and at monthly management board meetings. Relevant research findings were presented, including possible solutions for inspiration. Researchers were active partners in discussions of possible solutions, and advisers on 'state-of-the art' from an academic perspective.

\section{Case Description}

The case company is a large global supplier within the automation and control industry, and employs more than 30.000 people worldwide. The case study takes place at a business unit specialized in mass-production for industrial manufacturers, which employs around 600 employees and has a turnover on more than 2 mill standard products each year. The business unit has production facilities in China, 
Denmark (headquarters), Poland, and the United Kingdom, and more than 230 sales companies, agents and distributors worldwide. The business unit has four main product types: Fluid controls, pressure monitors \& controls, temperature monitors \& controls, and contactors and motor starters. Each year, the business unit receives around 150-300 customer requests for new products or customer change requests to existing products from their sales offices worldwide. The requests include varying degree of complexity, but in general there are about $60-70 \%$ simple change requests, $20-30 \%$ large changes to existing products, and 5-10\% classified as new products involving both new technology and radical innovation. Previously, the company has managed customer requests ad hoc in the technical service department, which is responsible for process management, including coordination and collaboration across involved functions. Technical service developed a request specification sheet and a stage-gate process model as a first take to manage the request process. Sales employees are advised to fill out the specification sheet, called the Customer Request Sheet (CRS), in the enquiry phase for request evaluation by technical service. Based on the specifications technical service evaluates the business potential, based on their knowledge on expected production costs. If they accept the request, the product is developed by the engineering department and sent to production for pre-production and quality test. Afterwards, the product is set up as a standard product in the system, and awaits the first customer orders before production is initiated.

During the collaboration period, the company sought to improve the success-rate of the process. Their aim of measure is a so-called 'hit-rate', which indicated 'how many of the products developed for market launch are ever sold'. In the beginning of 2010 the hit-rate was a staggering $40 \%$, meaning that customers never ordered $60 \%$ of the developed products. During the collaboration period, the company develops an increased understanding of their process, and due to implementation of improvement initiatives both to the process and governance of the process, the hit-rate in the end of 2012 was up to around $75-80 \%$, which was viewed as a grand success. As explained by the production facility manager in Denmark, the goal is not to reach $100 \%$ hit-rate, since this might indicate that they do not take enough chances.

\section{Results}

From an open-systems perspective request management is dependent on a strong governance structure to among others support the process across the internal and external barriers. Here we focus on deducing which governance aspects of request management are additional to governance of internally initiated ECM.

Strategic Governance Aspects - Product and market strategy of the company are identified to be affecting request management, thereby functioning as governance mechanisms. For instance, Alpha's newest market strategy devotes special focus to the water control markets, but excludes locomotive turbines. The direct effect on request management is that customers from the locomotive industries are now categorically rejected, while the amount of requests from water control customers is 
increasing at a global scale. Similarly the product strategy includes reduction of product variant generation in all areas and especially within the solenoid valve series, which is challenging the request management process that generates variants to the extent that older products are allowed to endure. The different strategies are in the case company found to develop deliberate tensions between strategic management boards. Compared to internally initiated ECM, an important finding from the case is that both product and market strategies not only affects the ECM process, but also has a direct effect on the customer relationship through the request management process. Every time a request is rejected or accepted, following the strategic guidelines, the customer relationship is either enhanced towards a strategic relationship or the Alpha is degraded/maintained as a standard product supplier.

Technological Governance Aspects - The information system functions as the platform of the request management process. The system includes PDM system, CAD/CAM programs, and a process management information system, which in Alpha is a SharePoint solution with shared documents. Compared to internally initiated ECM, request management includes the customer in process iterations. From a knowledge management perspective, the information system should enable knowledge sharing externally and internally. The case shows that in practice, the challenge is to open access to information systems without sharing too much internal information. The company is seeking to implement an information system for controlled external information sharing, but has not yet found a suitable solution. Today, they share product information by sending physical prototypes and drawings back and forth. The initial part of the process, which is part of the sales process, is managed through a SAP Customer Relationship Management (CRM)-system. The ideal solution according to the company, is one information platform to share the entire process, both internally and externally, that includes functionality to share both process and governance related information, while including the ability to manage information access and information sharing across the process.

Organizational Governance Aspects - The organization of Alpha is, like most industrial manufacturers, a functional machine bureaucracy. The request process is managed across functions with shifting and/or shared process ownership through the process activities. The functional setup includes a departmental segregation of competences relevant for the process. Compared to ECM-processes that often have one process owner and a dedicated team, the nature of the request management process generates a need for multiple iterations. The customers have unique domain knowledge about their needs and dependencies to customer products, which makes the iterations both intra- and inter-organizational adding to the complexity compared to internally initiated ECM. Roles and responsibilities include considerations in relation to the customer. The study shows that sales managers are responsible for financial negotiations and relationship management, while engineers and technical employees are in direct contact with customers for joint prototyping and product knowledge sharing. Hence, roles and responsibilities towards the customer differ according to the functions' responsibility area. 
People Governance Aspects - Skills and competencies, both concerning domain knowledge and in relation to managing the process, are vital for process performance. Having to do with request management, which most often increases the cultural differences of the involved, enhances the challenge of the people governance aspect. Globally distributed sales offices and customers make culture management an important management skill. For instance, process managers found that they have to be more formal and polite when communicating to Chinese and American sales employees, whereas a more informal tone is used to employees and customers in Scandinavian countries. Additionally to internally initiated ECM is the knowledge transfer from customers to the company, and the company's absorptive capacity in this regard. During process improvement initiatives, the company has increased ECM training on customer related aspects, including customer relationship management, value selling, and collaboration between local sales departments and headquarters.

Enabling Management Processes - Two management processes are identified as enablers, which are customer relationship management and demand chain management. These are an addition to the known ECM enabling processes including knowledge management, ECM portfolio management, resource management and visual management. Knowledge management as an enabling governance mechanism includes buyer-supplier knowledge sharing during the request management process. Request portfolio management includes overview of all requests and analysis of request management at the aggregated level including analysis of customer responses to rejected requests, requested products market performance, and knowledge transfer management. During the improvement period in Alpha, the incoming requests are pooled into similar technology and product type, using project portfolio management methods. Risk and impact assessment benefitted from pooling similar requests in calculating future production costs. For instance, Alpha continuously rejected requests for plastic valves due to a high investment in new production equipment. However, when the requests were pooled, they realized that in total the investment would be reasonable compared with future profitability, and based on the pooled impact analysis, Alpha invested in new production equipment for plastic valves. At the end of 2012, the turnover on plastic vales was still increasing, and the investment proved to be profitable. To manage the portfolio of potential requests, Alpha now uses an opportunity management application in their SAP-CRM system. Thereby, Alpha headquarters gains a global overview of potential requests, which is kept up to date through their local sales offices.

Request Management Processes - The request management process in Alpha includes complex problem solving with a large degree of iterations depending on the complexity of the customer request. In practice, process managers spend a large amount if time bypassing the linear process management model. Iterations to previous phases are part of complex change requests, however the iterations are not documented since the process model does not support back-loops. Thereby the process becomes clouded and it is unclear at what stage the request exactly is, because the model does not provide a visual representation of the iterations. Alphas senior process improvement manager proposes that an iterative process model with a circular 
design would support process management, however such a model has not yet been implemented in Alpha. Request management processes differs from internally initiated ECM processes by including the customer actively during the process. This study shows that customers in request management interact with employees at every process stage, generating iterations across the process' functional flow. Therefore, request management includes an interaction process revolving around a solution design, most often starting with a CAD/CAM drawing of a prototype and later a physical prototype. Based on the case study findings, a framework for request management has been developed (figure 2), adding the additional aspects to the findings on customer-initiated ECM from existing literature.

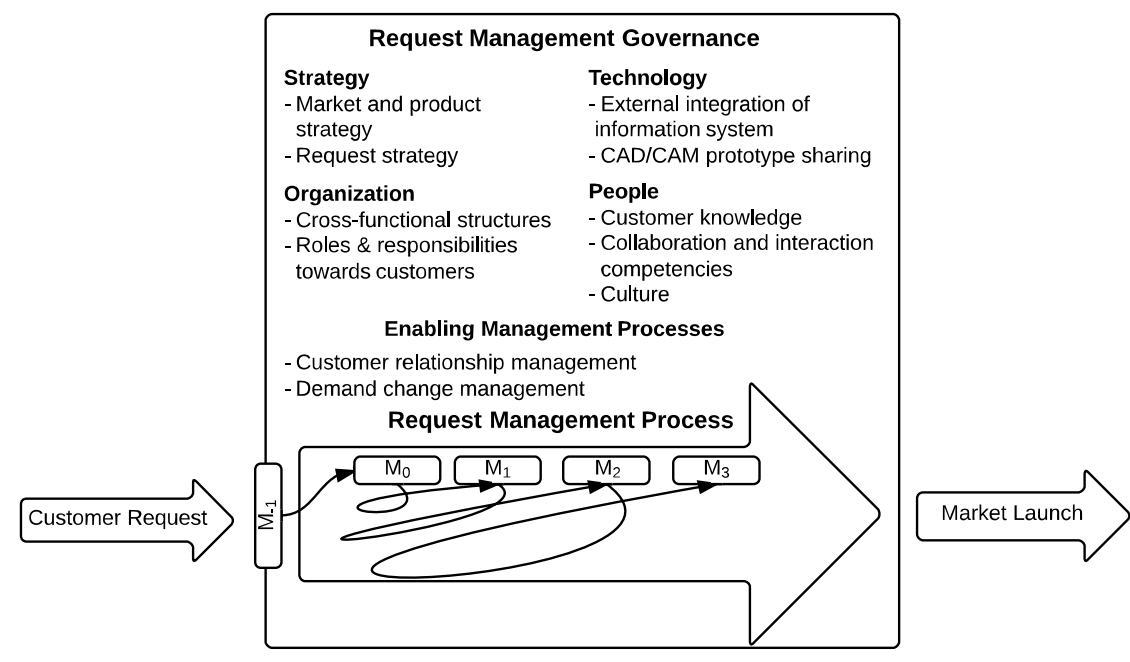

Fig. 2. Request management framework of additional governance and process aspects to internally initiated ECM

\section{Discussion and Conclusion}

This study initiates with an investigation of which process model and governance structure is appropriate for request management. The findings of a literature review show that an iterative process model should be applied to manage the intraorganizational and inter-organizational iterations. Inspired by ambitions of the case company and the latest research on ECM, an iterative task-based process model is proposed to Alpha. In essence, this model contains both the iterative and linear aspects of request management, while encompassing the process activities or tasks. The model is called 'Develop A Request Task Status (DARTS)', which fits the visual management principles [4, 8] having a logical structure and the goal of being a visual process management support artefact. The DARTS-model is presented in figure 3. 


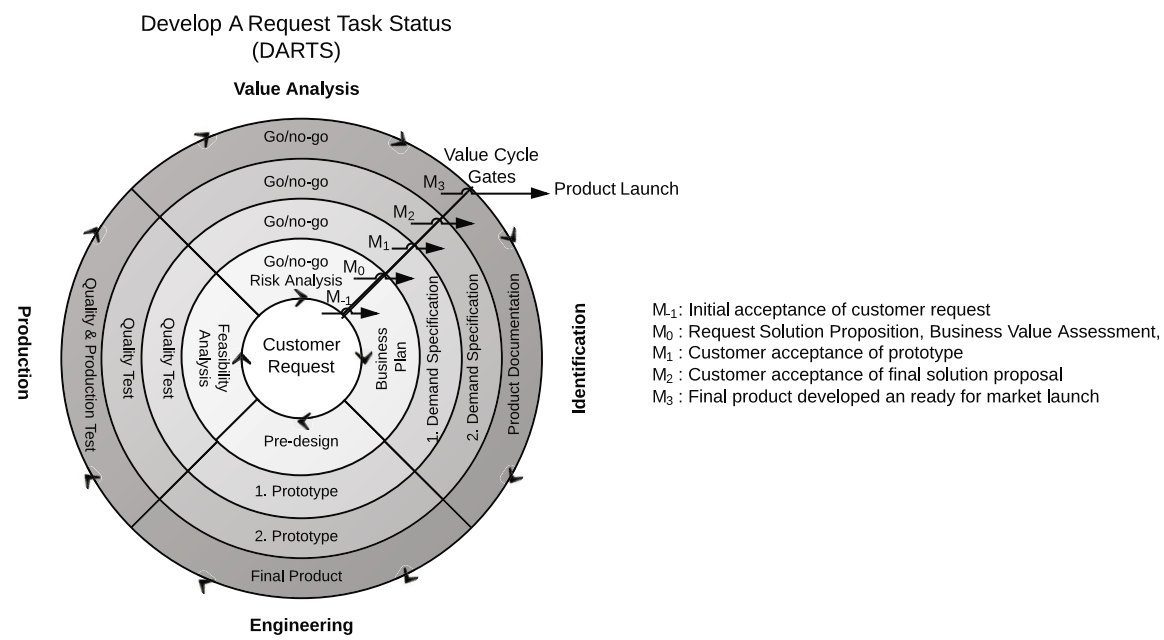

Fig. 3. Proposed task-based request process model

The model is the researchers' initial proposal of a request management process model that encompass the iterative nature identified through the study. The model has been proposed to Alpha representatives, and is in part being implemented in the current process governance setup. However, further research is recommended to test the model through implementation and evaluation, which the authors attempt to do in near future. The findings provide new insights on request management governance, which is included in the proposed request management framework. These include identification of relations between governance aspects affecting customer relationships, yet we still lack a complete overview of the interdependencies between governance and product performance, and further research on this subject is recommended. As for now, we have established the importance of additional customer-related governance aspects for request management compared to internally initiated ECM.

In this study, request management is framed in the context of ECM. However, customers may also request for new product development, thereby being the driver and active participant in the new product development process. This aspect of request management is relevant to consider conjointly with the ECM-process, and research is recommended uniting request management with customer-driven product development. Finally, this research points at information systems as an essential governance structure for request management, and proposed information systems solutions do exist that report of lead time reductions of up to $40 \%$ [2]. Hence, further research within information systems for request management is recommended. 


\section{References}

1. Büyüközkan, G., Arsenyan, J.: Collaborative product development: a literature overview. Production Planning \& Control 23, 47-66 (2011)

2. Wasmer, A., Staub, G., Vroom, R.W.: An industry approach to shared, crossorganisational engineering change handling-The road towards standards for product data processing. Computer-Aided Design 43, 533-545 (2011)

3. Tavčar, J., Duhovnik, J.: Engineering change management in individual and mass production. Robotics and Computer-Integrated Manufacturing 21, 205-215 (2005)

4. Jarratt, T.A.W., Eckert, C.M., Caldwell, N.H.M., Clarkson, P.J.: Engineering change: an overview and perspective on the literature. Research in Engineering Design 22, 103-124 (2011)

5. Hubka, V., Eder, W.E.: Theory of technical systems: a total concept theory for engineering design. Springer, Berlin (1988)

6. Fricke, E., Gebhard, B., Negele, H., Igenbergs, E.: Coping with changes: causes, findings, and strategies. Systems Engineering 3, 169-179 (2000)

7. Shankar, P., Morkos, B., Summers, J.D.: Reasons for change propagation: a case study in an automotive OEM. Research in Engineering Design, 1-13 (2012)

8. Eckert, C., Clarkson, P.J., Zanker, W.: Change and customisation in complex engineering domains. Research in Engineering Design 15, 1-21 (2004)

9. Dale, B.G.: The management of engineering change procedure. Engineering Management International 1, 201-208 (1982)

10. Huang, G.Q., Mak, K.L.: Current practices of engineering change management in UK manufacturing industries. International Journal of Operations \& Production Management 19, 21-37 (1999)

11. Von Bertalanffy, L.: General system theory: Foundations, development, applications. George Braziller, New York (1968)

12. Koh, E.C.Y., Caldwell, N.H.M., Clarkson, P.J.: A method to assess the effects of engineering change propagation. Research in Engineering Design, 1-23 (2012)

13. Maull, R., Hughes, D., Bennett, J.: The role of the bill-of-materials as a CAD/CAPM interface and the key importance of engineering change control. Computing \& Control Engineering Journal 3, 63-70 (1992)

14. Aurich, J., Rößing, M.: Engineering change impact analysis in production using VR. Digital Enterprise Technology, 75-82 (2007)

15. Ahmad, N., Wynn, D.C., Clarkson, P.J.: Change impact on a product and its redesign process: a tool for knowledge capture and reuse. Research in Engineering Design, 1-26 (2012)

16. Markus, M.L., Jacobson, D.D.: Business process governance. In: Handbook on Business Process Management 2, pp. 201-222. Springer (2010)

17. Leavitt, H.J.: Applied organizational change in industry: Structural, technological and humanistic approaches. In: March, J.G. (ed.) Handbook of Organizations, Rand McNally, Chicago (1965)

18. Jarratt, T., Eckert, C., Clarkson, P.J.: Development of a product model to support engineering change management. In: Proceedings of the TCME, pp. 331-344 (2004)

19. Pikosz, P., Malmqvist, J.: A comparative study of engineering change management in three Swedish engineering companies. In: Proceedings of Design Engineering Technical Conference, Atlanta, vol. 1 (1998) 
20. Hölttä, V., Mahlamäki, K., Eisto, T., Ström, M.: Lean Information Management Model for Engineering Changes. World Academy of Science, Engineering and Technology 42, 14591466 (2010)

21. Alblas, A., Wortmann, H.: Impact of product platforms on lean production systems: evidence from industrial machinery manufacturing. International Journal of Technology Management 57, 110-131 (2012)

22. Vaishnavi, V., Kuechler Jr., W.: Design science research methods and patterns: innovating information and communication technology (2008)

23. Holmström, J., Ketokivi, M., Hameri, A.-P.: Bridging Practice and Theory: A Design Science Approach. Decision Sciences 40, 65-87 (2009)

24. van Aken, J.E.: Management Research as a Design Science: Articulating the Research Products of Mode 2 Knowledge Production in Management. British Journal of Management 16, 19-36 (2005)

25. Baskerville, R.L., Myers, M.D.: Fashion Waves in Information Systems Research and Practice. MIS Quarterly 33, 647-662 (2009)

26. Van de Ven, A.H.: Engaged scholarship: A guide for organizational and social research, OUP Oxford (2007)

27. Järvinen, P.: Action Research is Similar to Design Science. Quality \& Quantity 41, 37-54 (2007)

28. C.S. Pierce, C. Harshorne, W. P.: Collected Papers. Harvard University Press (1931)

29. Iivari, J.: A Paradigmatic Analysis of Information Systems As a Design Science. Scandinavian Journal of Information Systems, 39-64 (2007)

30. Hevner, A.R., March, S.T., Park, J., Ram, S.: Design science in information systems research. Mis Quarterly 28, 75-105 (2004)

31. Kuechler, B., Vaishnavi, V.: On theory development in design science research: anatomy of a research project. European Journal of Information Systems 17, 489-504 (2008)

32. Meredith, J.R.: Hopes for the future of operations management. Journal of Operations Management 19, 397-402 (2001)

33. Auerbach, C.F., Silverstein, L.B.: Qualitative data: An introduction to coding and analysis. New York University Press, New York (2003)

34. Yin, R.: Case Study Research: Design and Methods. Sage, CA (1994) 